PUPIL: International Journal of Teaching, Education and Learning

ISSN 2457-0648

Bar Shalom E Specter, 2021

Volume 5 Issue 3, pp. 13-20

Received: 02 ${ }^{\text {nd }}$ March 2021

Revised: 18 th July 2021, 23 ${ }^{\text {rd }}$ August 2021

Accepted: 28 th September 2021

Date of Publication: 15 th November 2021

DOI- https://doi.org/10.20319/pijtel.2021.53.1320

This paper can be cited as: Bar Shalom, Y. E Specter, A. (2021). David Burns' TEAM CBT Therapy as A Tool for Educational Counselors. PUPIL: International Journal of Teaching, Education and Learning, 5 (3), 13-20.

This work is licensed under the CreativeCommons Attribution-NonCommercial 4.0 International License. To view a copy of this license, visit http://creativecommons.org/licenses/by-nc/4.0/ or send a letter to Creative Commons, PO Box 1866, Mountain View, CA 94042, USA.

\title{
DAVID BURNS' TEAM CBT THERAPY AS A TOOL FOR EDUCATIONAL COUNSELORS
}

\author{
Yehuda Bar Shalom \\ Prof. Dr., Trainer and Therapist, Ramat Gan Academic College, Hebrew University, Israel \\ yehudabar2@iac.ac.il
}

\author{
Amy Specter \\ Feeling Great Therapy Center \\ babyfreud@gmail.com
}

\begin{abstract}
In this short article, the authors present their views on the effectiveness of Dr. David Burns' TEAM therapy as an effective tool for educational counsellors in school settings. The authors are Yehuda Bar Shalom, who is both an academic who works in training counsellors and an educational counsellor in the field, draws from his experience as a TEAM therapist and trainer, and Amy Specter, who is a licensed marriage and family therapist who works at a high school for at-risk youth and also has a private practice working with teens and adults online in California. This paper should be seen as a practice-oriented account of two reflective practitioners.
\end{abstract}

\section{Keywords}

David Burns, TEAM Therapy, CBT, Educational Counseling 


\section{Introduction}

We live in an age in which the evidence on the effectiveness of CBT in treating disorders such as depression, anxiety, and addictions is abundant. Many would argue that the effectiveness of CBT treatments compares with the effectiveness of drug therapy. (Cuijpers, et al., 2013; David, et al., 2008). Taking into account the fact that many children and adolescents have no access to mental health services in the community, it would seem logical to have mental health providers in schools, such as educational counsellors and educational psychologists, learn to use effective CBT protocols for effective interventions. (Joyce-Beaulieu \& Sulkowski, 2019). After all, CBT teaches the consultee, the student, that if he or she makes changes in the way that she/he thinks about a certain situation/problem, then meaningful positive behavioural and emotional changes can occur (Graham, 2005). CBT School interventions have also been shown to be effective with minorities and at-risk youth. (Miranda, et al., 2007; Sapp, 1994; Sapp \& Farrell, 1995). In a way, the school counsellor utilizing CBT techniques can be seen as a coach who helps the student develop a positive "problem-solving thinking mode" (See Braswell \& Kendall 2001).

In this paper, we would like to recommend David Burns' TEAM CBT as an effective tool for School-based interventions that would be carried out by School Educational Counsellors. Dr. David Burns, who is perhaps Aaron Beck's most famous student, helped popularize Cognitive Behavioural Therapy with the publication of Feeling Good, an effective self-help book with many millions of copies being sold internationally in many languages, which has helped many individuals overcome depression and other mood problems and habits. (Burns, 1991) As counsellors' trainers, we have found out that this book and the new "Feeling Great" book (Burns, 2020) can be used as an effective manual for educational counsellors. Both offer the basic theory behind CBT, with "Feeling Great" further introducing TEAM concepts. Educational Counsellors can adapt the techniques to work with children, adolescents, and staff members in the school who encounter problems in diverse life situations. The books are useful because as part of learning, the Counsellors can practice resolving their problems using the books and have a feel on how the techniques would work with their school clients. In addition, educational counsellors can work with CBT manuals designed specifically to work with children (See for example Stallard, 2009). It is also important to mention, that effective, short-term techniques such as CBT appear as part of the expected competencies that school counsellors should be able to manifest in the training 
standards of the American School Counsellors Association, which serves as an important reference point for many educational counsellors training programs around the world (ASCA, 2021).

\section{TEAM CBT and Educational/School Counseling}

As stated in the previous section, CBT seems to be very effective as a tool to be used by educational counsellors and other therapists in educational settings. However, we would like to propose the idea that TEAM CBT, or TEAM therapy, developed by David Burns at Stanford in the last two decades, is a welcome new addition to the world of psychotherapy in general, and would be also a very efficient addition to the educational counselling profession. What does the TEAM in TEAM CBT stand for?

T- Testing

E - Empathy

A - Agenda Setting

M - Methods

The TEAM therapy approach, which we had the opportunity of studying directly with Dr. Burns and other TEAM masters such as Daniel Mintie, Matthew May, Maor Katz, Angela Krumm, Jill Levitt, Rhonda Barovksy, Heather Clague, and many more, is an integrative approach to mental health which increases the therapist's accountability by very accurate measurement (Testing).

Testing in Team uses very accurate scales to measure the client's moods before and after each session. The measurement strongly increases the effectiveness of the therapy, as the therapist can become aware of what exactly changed and did not change during the session, and between sessions. Another scale that we use in TEAM after each session is an evaluation of the session. In simple words, the client evaluates the therapist on his empathy (or lack of), the helpfulness of the session, and more. Again, in the TEAM model, the therapist takes it upon himself to increase his empathy skills, having the clients being his best teacher.

Empathy scores in the evaluation form are very important for the counsellor/therapist. In TEAM we find it very difficult to advance into agenda-setting or offering the client changes in thinking/feeling/behaviour without first establishing a perfect empathy with the client. The quality of empathy, as Carl Rogers stated, (Rogers, 1975) is a very strong predictor of the success of the therapy. 
But empathy can be improved! In TEAM training, the therapists practice the five secrets of effective communication which are:

- The Disarming Technique.

- Thought and feeling empathy.

- I feel.

- Inquiry.

- Affirmations.

The Disarming Technique is based on a paradoxical law of opposites. Usually, when we are attacked in any relationship (Including in a therapeutic relationship) we tend to defend ourselves. In the disarming technique, we make a strong effort to find the truth in the attack. When this happens, the attacker immediately ceases to believe in the attack. Many therapists find this paradoxical technique the most difficult to grasp, as they must let go of their ego.

Thought and feeling empathy means that the therapist tries to accurately paraphrase the client's words and tries to reflect the feelings that he picks up from the client. ("You are telling me that your uncle took you out of the family business and I imagine that you may be feeling frustrated and angry, am I getting you right?)

I feel statements are simply statements that describe the listener's feelings when he hears the other person talk. In TEAM we believe that I feel statements have the potential of making any relationship, including the therapeutic relationship, deeper and more genuine.

Inquiry means that the therapist or the participant in the relationship asks gentle, openended questions, to further understand the other's point of view.

Affirmations mean all that we find about the other person that is positive and wonderful. These techniques are very well explained in David Burns' book Feeling Good Together (Burns, 2008). In TEAM therapy training, therapists practice with each other using these techniques, To strengthen their empathy muscles. In a school counselling setting, empathy skills are very important, as it is useful for the clients in the school setting to have the counsellor create a fast and accurate empathic relationship, to allow brief, yet meaningful, therapeutic interventions.

Agenda Setting in TEAM therapy Agenda setting is a paradoxical process, done in TEAM therapy after the client feels understood by the therapist (perfect empathy - which is also measured by the therapist). In paradoxical agenda setting, the therapist joins in with the patient in finding all the good reasons not to change. This paradoxical agenda-setting process connects very 
well to one of the biggest hindrances to the therapeutic processes, which is trying to help. David Burns' position on the importance of having the client ask for help after we explored with him/her all the good reasons not to change, resonates well with Miller and Rollnik's warning on the need to avoid the "righting reflex", the attempt to convince the client that the change is favourable and necessary, which immediately puts the client in an oppositional attitude, arguing against the therapist, who takes the position in favour of the change, for all the good reasons not to change (Burns, 2020, Miller \& Rollnick , 2013 Mintie \& Staples, 2018).

\section{Two Examples}

\subsection{Yehuda's Example}

More than a decade ago, I switched from being a researcher of excellent schools in Israel (Bar Shalom 2006) To an educational counsellor in one of the schools he investigated. The Kedma School has enabled me to use TEAM therapy in many settings, both with staff, parents, and school students. In a very recent example, Ronnie, a 17-year-old, came to see me after he was sent home for using physical violence against one of his peers. I used the Testing part in TEAM to see what his most dominant emotions were, and indeed, anger was in the highest score. When I was sure that my empathy scores are at the highest level, we proceeded to discuss the possibility to learn more socially adaptable reactions to his peers' verbal abuse. However, we first checked all the good reasons to retaliate with physical violence. This was very surprising for Ronnie, as he was always judged by adults. In this case, it was him, after using a TEAM technique called Cost-Benefit Analysis (pros and cons to continuing with violence, in his case) who asked me to help him to change his reactions. We used TEAM techniques and methods such as Identifying the distortions, the double standard technique (what would you tell a good friend) and he started to use the five secrets of effective communication as a tool to deal with his friends' comments. In a month, violence disappeared from his interactions with his peers.

\subsection{Amy's Example}

I love teaching the 5 Secrets of Effective Communication to students. I was a guest teacher weekly in a career class and we would use the 5 Secrets to help the students brainstorm effective responses they could give to a difficult customer, coworker, and employer situations they had experienced the week before. For example, Kayla worked at a fast-food restaurant and had a customer complain that their food was not made fast enough. Kayla came up with this response 
"You are right that your food came out slower than expected (disarm, thought empathy). I imagine you are feeling annoyed and irritated (feeling empathy). I feel disappointed that we couldn't get your order to you quicker (I feel). I have seen you in here before and I know that you are a loyal customer at our restaurant and probably have some important things you are doing tonight that have been delayed (affirmation). Is there anything I can do now to help make the situation right for you? (inquiry)"

Kayla later reported that having the ability to use the five secrets with challenging customers had made it possible for her to stay at this job as she had been fired from a previous job after losing her temper in a similar situation.

Another student in the career class had a challenging boss who kept asking her to work overtime. She didn't know how to respectfully say no and was feeling tired at school due to the late hours she kept working. The students in the class helped her brainstorm this response.

"You would like me to work an extra 3 hours tonight and I can see how that would help things run more smoothly here (thought empathy, disarm). I feel so disappointed that I am unable to stay and help out (I feel). You might be feeling a little bit annoyed that I can't stay and probably am overwhelmed right now (feeling empathy). I respect how hard you work and what a great manager you are (affirmation). Is there anything I can do to help you brainstorm how to cover the work that needs to get done tonight? (inquiry)"

I worked with a student Mark who had extreme anxiety that prevented him from attending school regularly and enjoying his life. He loved to draw so I asked him to draw a character who represented all of the positives of his anxiety. He came up with Anxiety Man - a super anxious superhero who used his rumination and glass half full thinking to save people from terrible events. Mark then drew Chill Dude, who represented the negatives of losing his anxiety. Chill Dude was so relaxed and never really paid attention to anything. Chill Dude was hit by a bus because he wasn't worried about looking when crossing the street. I was able to empathize with all of the good reasons to keep the anxiety so he knew that I was not just another adult in his life telling him what to do. I truly understood and respected all of the good thing's anxiety did to keep him safe. Once Mark externalized all of the benefits of keeping his anxiety and the negatives of losing it, paradoxically he was able to start working on strategies to help him have a different relationship to his difficult feelings. 


\section{Summary and Conclusions}

To sum up this short article, it seems that the TEAM therapy model, is a humanistic, integrative approach, with a very common-sense design, which may help educational counsellors in providing effective short-term therapy in school settings. It overcomes one of the major problems of CBT in the past, which is not dealing with the patient's resistance. It seems that accurate Testing, Empathy, and especially Agenda Setting (Paradoxical melting away of resistance) are the elements that make the more than 50 methods and techniques effective to help the client in the school setting, whatever his problem may be. School Counselors tend to have a very heavy workload, and these effective techniques can be a useful additional tool to their set of advanced tools. We recommend School Counselors and other therapists in related fields explore and try these techniques in their practice and setting.

\section{For more information on TEAM therapy}

Dr. David Burns' website - https://feelinggood.com/

Feeling Great Therapy Center FGTC (feelinggreattherapycenter.com)

Training in TEAM therapy. The Feeling Good Institute - http://www.feelinggoodinstitute.com/

The author's (Yehuda) website TEAM therapy training - www.yehudabarshalom.com

The author's (Amy) website www.amyspecter.com

\section{REFERENCES}

Asca, (2021). ASCA School Counselor Professional Standards \& Competencies. The American School Counselor Association. www.schoolcounselor.org

Braswell, L., \& Kendall, P. C. (2001). Cognitive-behavioural therapy with youth. In K. S.

Dobson (Ed.), Handbook of cognitive-behavioural therapies (2nd ed.) (Pp. 246- 294).

New York: The Guilford Press.

Burns, D. (1999). Feeling good: The new mood therapy. New York: Avon Books.

Burns, D. D. (2008). Feeling Good Together. New York: Broadway Books.

Burns, D. D. (2020) Feeling Great. Eau Claire. WI.

Cuijpers P, Dekker J, Hollon DS, Andersson G. (2009) Adding psychotherapy to pharmacotherapy in the treatment of depressive disorders in adults: A meta- 
analysis. Journal of Clinical Psychiatry. 70 (9),1219-1229. https://doi.org/10.4088/JCP.09r05021

David D, Szentagotai A, Lupu V, Cosman D. (2008). Rational emotive behaviour therapy, cognitive therapy, and medication in the treatment of major depressive disorder: à randomized clinical trial, posttreatment outcomes, and six-month follow-up. Journal of clinical psychology. 64(6), 728-746. https://doi.org/10.1002/jclp.20487

Graham, P. (2005). Jack Tizard lecture: Cognitive behaviour therapies for children: Passing fashion or here to stay? Child and Adolescent Mental Health, 10, 57-62.

Joyce-Beaulieu, D, iana, Sulkowski, M. L., (2019). Cognitive Behavioral Therapy in K-12 School Settings, 2nd Edition. New York: Springer. https://doi.org/10.1891/9780826183132

Miller, W. R., \& Rollnick, S. (2013). Applications of motivational interviewing. Motivational interviewing: Helping people change (3rd edition). New York: Guilford Press.

Mintie, D, Staples, J.K, (2018). Reclaiming Life After Trauma: Healing PTSD with CognitiveBehavioral Therapy and Yoga. Rochester, Vermont: Healing Arts Press

Miranda, A., Webb, L., Brigman, G., \& Peloso, P. (2007). Student Success Skills: A promising program to close the academic achievement gap for African American and Latino students. Professional School Counseling, 10, 490-497. https://doi.org/10.1177/2156759X0701000506 https://doi.org/10.5330/prsc.10.5.rx6g3g7141w2310q

Rogers, C. R. (1975). Empathic: An unappreciated way of being. The Counseling Psychologist, 5(2), 2-10. https://doi.org/10.1177/001100007500500202

Sapp, M. (1994). Cognitive-behavioural counselling: Applications for African American middle school students who are academically at-risk. Journal of Instructional Psychology, 21(2), 161-172.

Sapp, M., \& Farrell, W. (1995). Cognitive-behavioural therapy: Applications for African American middle school at-risk students. Journal of Instructional Psychology, 22(2), 169178

Stallard, P. (2009). CBT with children, adolescents, and families. Anxiety: Cognitive behavioural therapy with children and young people. Routledge/Taylor \& Francis Group. 